\title{
Stress echocardiographic assessment of mitral valve function repaired using rough-zone trimming
}

\author{
Yohsuke Yanase*, Nobuyuki Takagi, Hiroyuki Yamada, Toshitaka Watanabe, Mayuko Uehara, Kazutoshi Tachibana, \\ Yasuko Miyaki, Toshiro Ito and Tetsuya Higami
}

\begin{abstract}
Background: We invented novel mitral valve repair technique; rough-zone trimming procedure (RZT) for anterior mitral valve prolapse. Prolapse site was resected in obtuse triangle shape and sutured edges to creates deep coaptation and improves regurgitation. Though it is simple and reproducible technique, functional mitral stenosis is a risk. Valve function and hemodynamics were investigated using dobutamine stress echocardiography (DSE) in patients after mitral valve repair using RZT.
\end{abstract}

Methods: Patients underwent RZT for the anterior mitral valve ( $A M L, n=10$ ), quadrangular resection $(Q R)$ of the posterior mitral valve (PML; $n=4), R Z T+Q R$ of bileaflet valves (bileaflet; $n=4)$ and healthy individuals (control; $\mathrm{n}=10$ ) and were assessed by DSE (doses up to $20 \mu \mathrm{g} / \mathrm{Kg} / \mathrm{min}$ ). Echocardiographic data including mitral valve area (MVA), mitral valve mean pressure gradient (MVmeanPG), and systolic pulmonary artery pressure (sPAP) were measured at rest and at peak stress.

Results: Rest/stress MVA $\left(\mathrm{cm}^{2}\right)$, MVmeanPG $(\mathrm{mmHg})$ and SPAP $(\mathrm{mmHg})$ were $2.8 \pm 0.4$ and $3.4 \pm 0.3,3.3 \pm 1.1$ and $7.4 \pm 4.1$, and $25.7 \pm 4.7$ and $49.1 \pm 4.1$, respectively, in the AML group. Dobutamine stress increased all parameters but not to pathological levels. The results were similar to those of the other groups after mitral valve repair, whereas MVA was larger and MVmeanPG was lower in the control than in the AML group.

Conclusions: Valve repair using RZT does not pathologically obstruct the mitral valve, either at baseline or during dobutamine stress, and does not affect valve hemodynamics and reserve.

Keywords: Mitral regurgitation, Mitral valve repair, Echocardiography, Heart valve, Surgery techniques

\section{Background} Introduction

Mitral valve repair rather than replacement has become the first choice of surgical treatment for mitral valve regurgitation because unnecessary of anticoagulant therapy and restoration of left ventricular function. Several techniques to repair the mitral valve have been presented and we invented a novel mitral valve repair technique (rough-zone trimming: RZT) to treat anterior mitral valve prolapse. The prolapse site is resected in RZT within a small obtuse triangle shape limited to the rough zone and re-sutured edges. This creates deep coaptation and prevents regurgitation. Among repaired mitral valves in 96 patients between February 2007 and January 2013, 49 of

\footnotetext{
* Correspondence: yanasey@sapmed.ac.jp

Departmetnt of Cardiovascular Surgery, Sapporo Medical University of Medicine, South 1, West 16, Chuo-ku, Sapporo, Hokkaido 060-8543, Japan
}

them were repaired using RZT (diseased anterior mitral leaflet, $\mathrm{n}=25$; diseased bileaflet, $\mathrm{n}=24$ ). The early and midterm ( $>12$ months) outcomes of RZT for the repair of the anterior mitral leaflet were satisfactory (Figure 1).

\section{Purpose}

Although repair of an anterior mitral leaflet prolapse remains challenging, RZT has generated reproducible and reliable results. But functional mitral stenosis remains a potential risk. Here, we applied dobutamine stress echocardiography (DSE) to assess the hemodynamics of mitral valves that were repaired using RZT.

\section{Methods \\ Patients}

All patients underwent mitral valve repair of anterior leaflets between February 2007 and January 2013. Patients 


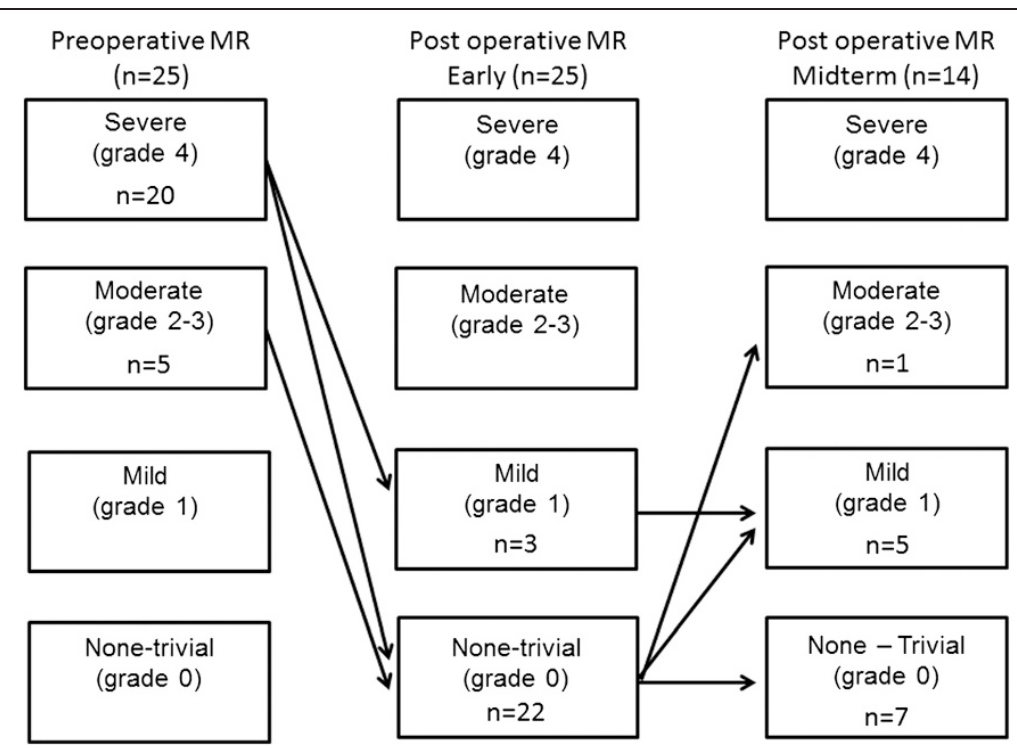

Figure 1 Preoperative and postoperative echocardiographic grade of mitral regurgitation (MR). Preoperative MR grades were severe and moderate 20 and 5 patients, respectively. Mitral valves were repaired using rough-zone trimming (RZT). All grades improved to below mild MR grades within early postoperative period of 30 days. By mid-term (>12 months), 13 of 14 patients had better than mild MR. Only one patient worsened to moderate MR because of progressive sclerotic valve changes.

who underwent mitral valve repair for posterior leaflets, bileaflets and healthy controls were also included. The elimination criteria comprised serious disorders such as angina pectoris, severe hypertension, arrhythmia, cerebral bleeding, aortic aneurysm, aortic dissection, $<6$ months after mitral valve repair and withholding written consent to participate. Our institutional review board and medical ethics committee approved the present study (approval number: 25-2-40 and 25-1147).

\section{Surgical procedure}

Cardiopulmonary bypass was established via a full median sternotomy, the ascending aorta, and the superior and inferior vena cava were directly cannulated, the ascending aorta was cross-clamped, and then antegrade and retrograde cardioplegic solution was injected. The mitral valve was exposed via a conventional left atriotomy.

The mitral valve configuration and the prolapse site were checked using saline injection. Anterior and posterior mitral commissures were compressed using horizontal mattress sutures (3-0 polyester with pleget). We ensured that the stitch was bigger on the posterior annular side, which led to not only deeper leaflet coaptation, but also the ability to draw the posterior leaflet upwards to the same plane as the anterior leaflet. Thus, the prolapse site became obvious. The technique is similar to Kay sutures [1], but the concept slightly differs, and we named it the enhanced stay suture (ESS; Figure 2). After ESS, details of prolapse sites were reconfirmed by saline injection and the mitral valve was repaired.

\section{Mitral valve repair for anterior leaflet}

We used the RZT to repair prolapse sites that were located in the anterior leaflet. Prolapsed sites were resected in the shape of an obtuse triangle and confined to the rough zone. The resected height of the triangle is confined to the rough-zone (not cut into the clear zone). The resected base length of the triangle is only the degenerated and thickened area. Resected edges were then brought together with interrupted 6-0 monofilament sutures. The repaired site of the valve leaflet was brought down into the left ventricular side to acquire deeper coaptation, which improved mitral valve regurgitation. (RZT; Figure 3).

\section{Mitral valve repair for posterior leaflet}

We repaired prolapse sites in posterior leaflets using quadrangular resection $(\mathrm{QR})$ [2]. The posterior annulus was stitched using 3-0 polyester pledgeted compression sutures and resected edges were closed with interrupted 6-0 monofilament sutures.

\section{Mitral valve repair for anterior combination with posterior leaflet}

We repaired prolapse sites in the anterior and posterior leaflets (bileaflet) using both RZT and QR techniques.

After repairing mitral valve leaflets, annuloplasty proceeded using a suitable flexible band to prevent future annular dilation. Since the annular size was adjusted by ESS, we did not apply annular plication with the flexible band. After completing a series of valve repairs procedures, we performed retrograde cardioprotective beating 
a

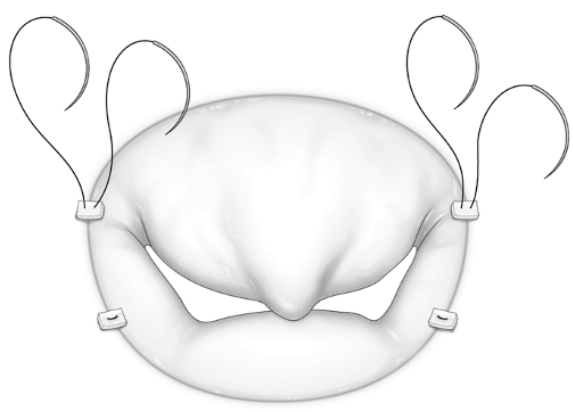

b

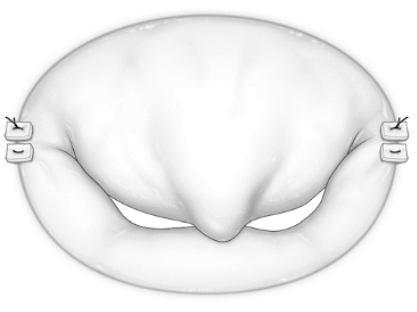

Figure 2 Schema of enhanced stay sutures (ESS). Mitral valve leaflet and medial site of anterior leaflet is elongated and prolapsed. (a) Horizontal mattress sutures (3-0 polyester suture with pledgets) for anterior and posterior commissures. Stitches pulled bigger bites out of posterior annular side. (b) After ESS. Anterior and posterior commissures are compressed and coaptation is deeper. ESS allowed not only deeper coaptation, but also pulled posterior leaflet upwards to the same plane as anterior leaflet by taking bigger bites out of the posterior annular side. This also rendered prolapse sites highly visible.

test (RC-beating test) to check for residual regurgitation [3]. Under aortic cross-clamping and before closing the left atrium, cardiac perfusion was retrogradely started via the coronary sinus and cardiac beating was started to directly visualize and evaluate residual regurgitation. Repair of the mitral valve repair was completed after the absence of leakage was confirmed.

\section{Echocardiography}

One investigator evaluated all patients using a Phillips iE33 ultrasound device (Royal Philips Electronics, Amsterdam, Netherlands). Left ventricular diameters (LVEDD, LVESD), volumes (LVEDV, LVESV), ejection fraction (EF) derived from the Teichholz and Simpson rule. Cardiac output was calculated as stroke volume $($ LVEDV - LVESV) $\times$ heart rate $(\mathrm{HR})$. The mitral valve area (MVA) was calculated using the pressure half-time (PHT) method. Mean and peak transmitral pressure gradients (MVmeanPG, MVmaxPG) were determined using continuous wave Doppler echography. Systolic pulmonary pressure (sPAP) was derived from the maximal velocity of the tricuspid Doppler tracing at a fixed right atrial pressure of $10 \mathrm{mmHg}$. The degree of mitral regurgitation (MR) was estimated from the maximum regurgitant jet area (MRA) in color flow Doppler echocardiograms.

The protocol for dobutamine stress echocardiography is described below. All patients were placed in the left decubitus position for echocardiographic assessment at rest. Thereafter, the DSE study was started by intravenously infusing dobutamine $(5 \mu \mathrm{g} / \mathrm{Kg} / \mathrm{min})$ using a syringe driver. Blood concentration were allowed to stabilize for five minutes and then the first stage of the echocardiographic study started by increasing the dobutamine dose in $5 \mu \mathrm{g} / \mathrm{Kg} / \mathrm{min}$ increments every three minutes to a maximum of 10,15 and $20 \mu \mathrm{g} / \mathrm{Kg} / \mathrm{min}$. Echocardiographic data were collected at each stage. Blood pressure, oxygen saturation and electrocardiographic findings were continuously monitored throughout the study, which was stopped when either of the following end-points was achieved: target heart rate of $>85 \%$ of maximum predicted (220 - age) or the dobutamine dose was maximal $(20 \mu \mathrm{g} /$ $\mathrm{Kg} / \mathrm{min})$. The study was discontinued if any of the following events occurred: intolerable symptoms (chest pain or progressive dyspnea), limiting asymptomatic side effects a

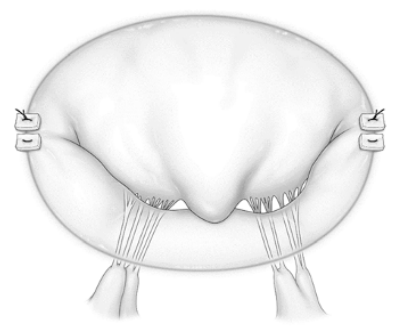

b

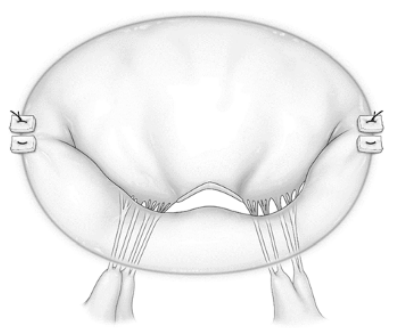

$\mathrm{c}$

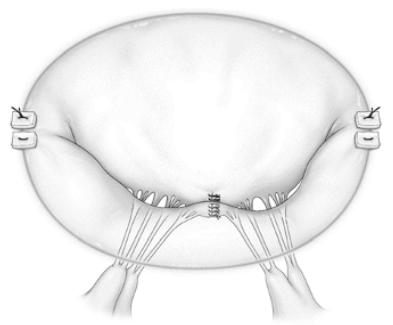

Figure 3 Schema of rough-zone trimming (RZT). (a) Medial scallop (A2) of anterior mitral valve leaflet (AML) is elongated and prolapsed after previous ESS. (b) Prolapsed A2 site resected in shape of obtuse triangle limited to rough-zone. (c) Resected edges repaired with 6-0 monofilament sutures. Repaired site of valve leaflet was taken down into left ventricular side and deeper coaptation improved mitral valve regurgitation. 
such as systolic or diastolic blood pressure of $>220$ and/ or $>120 \mathrm{mmHg}$, hypotension defined as a relative or absolute $>30 \mathrm{mmHg}$ decrease blood pressure, supraventricular tachycardia or atrial fibrillation, ventricular tachycardia or frequent, polymorphous premature ventricular beats. Acquired data were verified according to the American College of Cardiology/American Heart guidelines for the management of patients with valvular heart disease (2008) [4] in which MVA $<1.0 \mathrm{~cm}^{2}$, or MVmeanPG under stress of $>15 \mathrm{mmHg}$, or sPAP under stress of $>60 \mathrm{mmHg}$ were defined as severe mitral stenosis requiring surgery.

The severity of MR was classified as none or trivial (MRA $\leq 2.0 \mathrm{~cm}^{2}$; grade 0), mild (MRA $>2.0 \leq 4.0 \mathrm{~cm}^{2}$; grade 1 ), moderate (MRA $>4 \leq 6 \mathrm{~cm}^{2}$; grade 2 ), moderately severe (MRA $>6 \leq 8 \mathrm{~cm}^{2}$; grade 3 ) and severe (MRA > $8 \mathrm{~cm}^{2}$; grade 4) [5].

\section{Statistical analysis}

All values are expressed as means \pm standard deviation. Rest and stress data were compared using a paired $t$-test. Between-group comparisons were analyzed using Welch's $t$-test. $\mathrm{P}<0.05$ was considered statistically significant.

\section{Results}

Nineteen patients with repaired mitral valves and 11 healthy control individuals participated in the DSE study. Paroxysmal supraventricular tachycardia developed in one patient after mitral valve repair for the anterior leaflet and accelerated ideo-ventricular rhythm developed in one healthy control. Both opted out of the study and their data were excluded. Therefore, the DSE study was completed in 10 patients in the AML group, four each in the PML and bileaflet groups and in 10 healthy controls (Table 1) and implemented at an average of 20.7 (7.2-40.9), 32.1

Table 1 Patients' characteristics

\begin{tabular}{lllll}
\hline & $\begin{array}{l}\text { AML } \\
(\mathbf{n = 1 0})\end{array}$ & $\begin{array}{l}\text { PML } \\
(\mathbf{n}=\mathbf{4})\end{array}$ & $\begin{array}{l}\text { Bileaflet } \\
(\mathbf{n = 4})\end{array}$ & $\begin{array}{l}\text { Control } \\
(\mathbf{n}=\mathbf{1 0})\end{array}$ \\
\hline Sex (M:F) (n) & $8: 2$ & $4: 0$ & $3: 1$ & $10: 0$ \\
Age (y) & $56.5 \pm 19.3$ & $59.0 \pm 6.1$ & $53.3 \pm 6.1$ & $25.0 \pm 3.7$ \\
$\begin{array}{l}\text { Infective endocarditis (n) } \\
\text { Annuloplasty }\end{array}$ & 1 & 0 & 1 & - \\
$\begin{array}{l}\text { ring size (mm) } \\
26 \text { (n) }\end{array}$ & 2 & 1 & 1 & - \\
27 (n) & 0 & 1 & 0 & - \\
28 (n) & 3 & 1 & 2 & - \\
30 (n) & 1 & 1 & 1 & - \\
No annuloplasty & 4 & 0 & 0 & - \\
$\begin{array}{l}\text { Residual mitral } \\
\text { regurgitation }\end{array}$ & & & & - \\
None-Trivial (grade 0) (n) & 9 & 4 & 3 & - \\
Mild (grade 1) (n) & 1 & 0 & 1 & - \\
\hline
\end{tabular}

$\mathrm{AML}$, anterior mitral leaflet; $F$, female; $M$, male; $P M L$, posterior mitral leaflet.
(9.2-54.3) and 22.4 (7.3 - 35.0) months in these groups, respectively.

The degree of MR was below mild in all patients at rest and did not worsen in any of them with stress. Systolic anterior movement (SAM) also did not appeared at rest and with stress in all patients. Hemodynamic data such as heart rate, systolic blood pressure and cardiac output were significantly increased in all groups. The rest/ stress values for MVA $\left(\mathrm{cm}^{2}\right)$ in the AML, PML, bileaflet and control groups were $2.8 \pm 0.4 / 3.4 \pm 0.3,(p=0.0005)$, $2.8 \pm 0.3 / 3.2 \pm 0.3,(\mathrm{p}=0.001), 2.5 \pm 0.1 / 2.9 \pm 0.1,(\mathrm{p}=0.022)$ and $4.1 \pm 0.4 / 5.1 \pm 0.5,(\mathrm{p}=0.0001)$, respectively (Figure 4$)$. The MVmeanPG ( $\mathrm{mmHg}$ ) in the AML, PML, bileaflet and control groups were $3.3 \pm 1.1 / 7.4 \pm 4.1,(\mathrm{p}=0.0026) ; 5.5 \pm$ $1.0 / 10.5 \pm 2.4, \quad(\mathrm{p}=0.0058) ; 3.5 \pm 1.7 / 8.8 \pm 3.1, \quad(\mathrm{p}=0.0146)$ and 1.1 $\pm 0.3 / 3.6 \pm 0.7,(\mathrm{p}<0.0001)$, respectively (Figure 5). The sPAP (mmHg) in the AML, PML, bileaflet and control groups were $25.7 \pm 4.7 / 49.1 \pm 4.1, \quad(\mathrm{p}<0.0001) ; 30.0 \pm 1.4 /$ $47.0 \pm 1.4 ; 28.3 \pm 1.9 / 44.8 \pm 2.1,(\mathrm{p}=0.0034)$ and $26.9 \pm 2.3 /$ $43.9 \pm 7.6,(\mathrm{p}=0.0001)$; respectively (Figure 6$)$. The MVA, MVmeanPG and sPAP were significantly increased at peak stress in all groups (Table 2), but severe functional mitral stenosis requiring re-operation was not identified in any of the groups.

We compared rest/stress MVA, MVmeanPG and sPAP between the AML and the other groups. Though the stress SPAP was lower for the Bileaflet group than for the AML group, other data did not show hemodynamic disadvantage of the AML group compare with other mitral valve repair groups (Table 3). The rest/stress MVA was significantly larger for the control than for the AML group. The rest/stress MVmeanPG was significantly lower for the control than for the AML group. Otherwise sPAP did not significantly differ between the AML and control groups.

\section{Discussion}

\section{Summary of current mitral valve repair}

Mitral valve repair has become the preferred surgical treatment for MR and although previously challenging for treating the diseased anterior leaflet [6], newer methods such as artificial chordal implantation [7] and the edgeto-edge method [8] have improved outcomes $[9,10]$. However, some technical difficulties such as adjusting the length of artificial chordae during implantation and mitral stenosis are concerns in the edge-to-edge method. We overcame these problems using the simple and reproducible RZT with ESS.

\section{Novel mitral valve repair technique "Rough-zone trimming \& Enhanced stay suture"}

The conventional triangular resection procedure cuts into the clear zone of the anterior leaflet and resects a large leaflet area. Thus, there is a risk of dehiscence of 


\section{Mitral Valve Area}

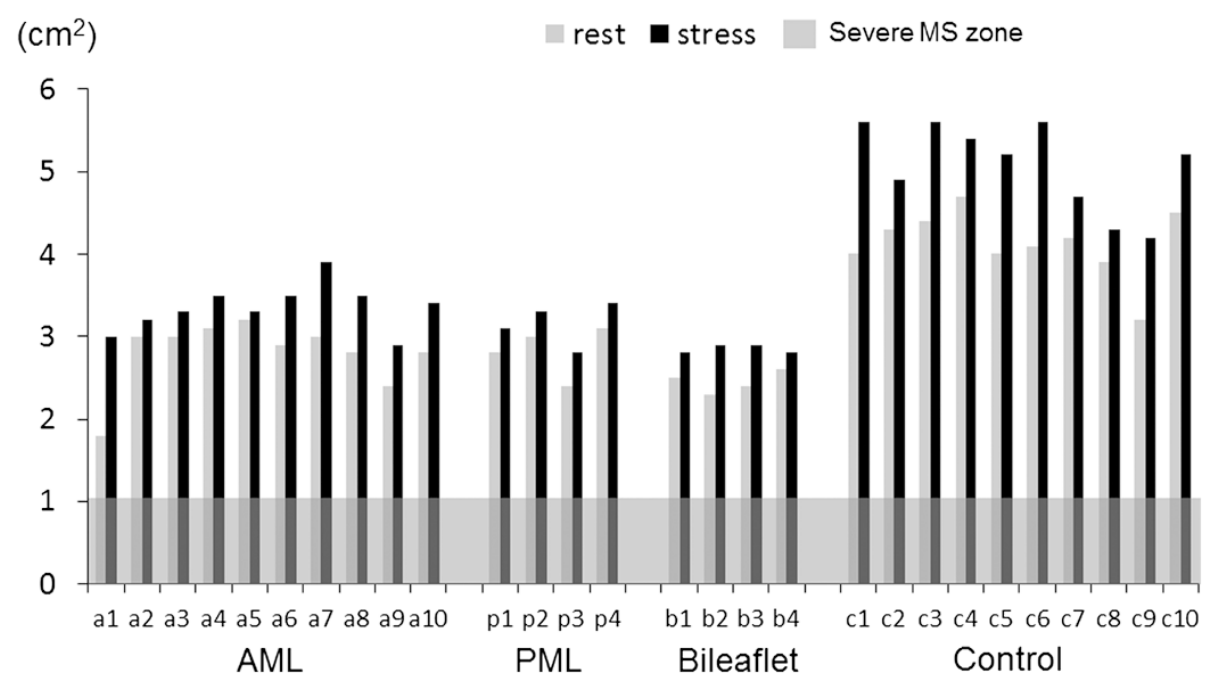

Figure 4 Echocardiographic data of mitral valve area (MVA). Echocardiographic data of mitral valve area (MVA) at rest and peak stress in $\mathrm{AML}, \mathrm{PML}$, bileaflet and control groups.

suture line and severe mitral stenosis. In RZT, since the clear zone is preserved, flexibility of the anterior leaflet is maintained and the dehiscence of suture line can be avoided. By enhanced stay suture (ESS), though the posterior leaflet and posterior annuals are drawn to the anterior leaflet, the posterior leaflet is compressed and the posterior leaflet height is also slightly reduced. RZT can also reduce excessed degenerated rough-zone of anterior leaflet by resection. These factors may contribute to prevention of occurrence of SAM. The outcomes of this procedure for 25 and 24 diseased anterior mitral and diseased bileaflets, respectively, between February 2007 and January 2013 were favorable. There is no case of suture dehiscence and SAM.

In RZT, resected area of the anterior leaflet was small. We have data for sizes of resected obtuse triangle segments $(n=35)$. Mean height of the triangles was $4.7 \pm 1.9 \mathrm{~mm}$ and mean base length of the triangles was $12.8 \pm 6.7 \mathrm{~mm}$. However, the resection and suture components of the technique confer risk of creating

\section{Mitral Valve mean Pressure Gradient}

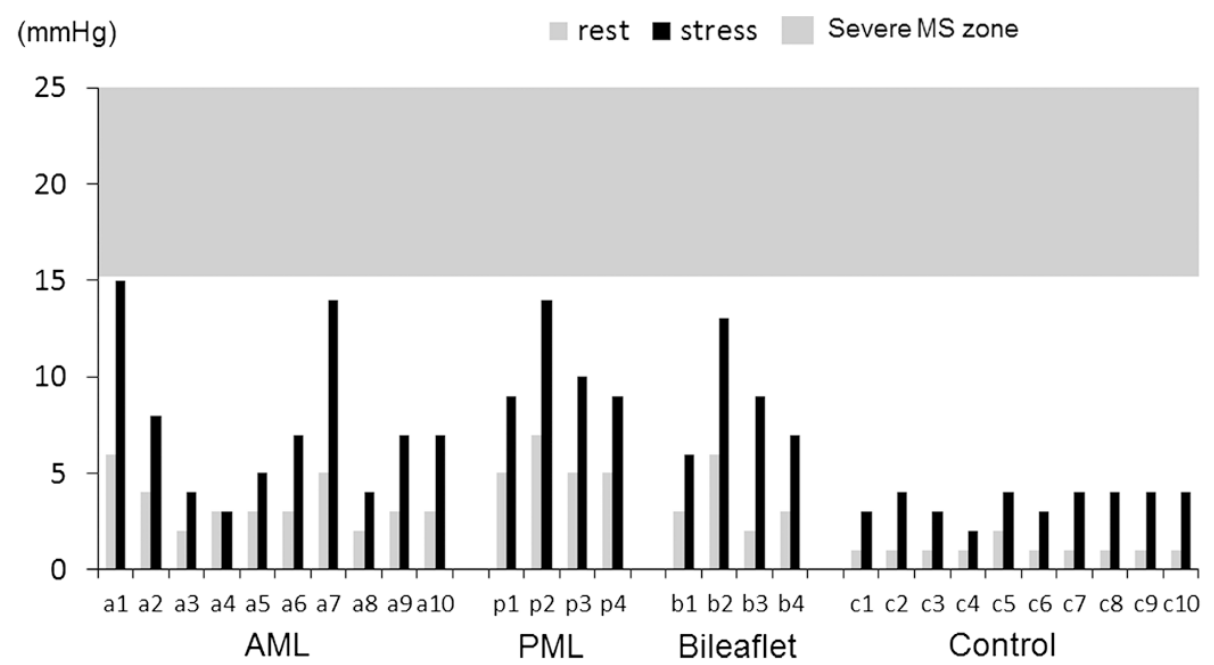

Figure 5 Echocardiographic data of mitral valve mean pressure gradient (MVmeanPG). Echocardiographic data of mitral valve mean pressure gradient (MVmeanPG) at rest and peak stress in AML, PML, bileaflet and control groups. 


\section{Systolic Pulmonary Artery Pressure}

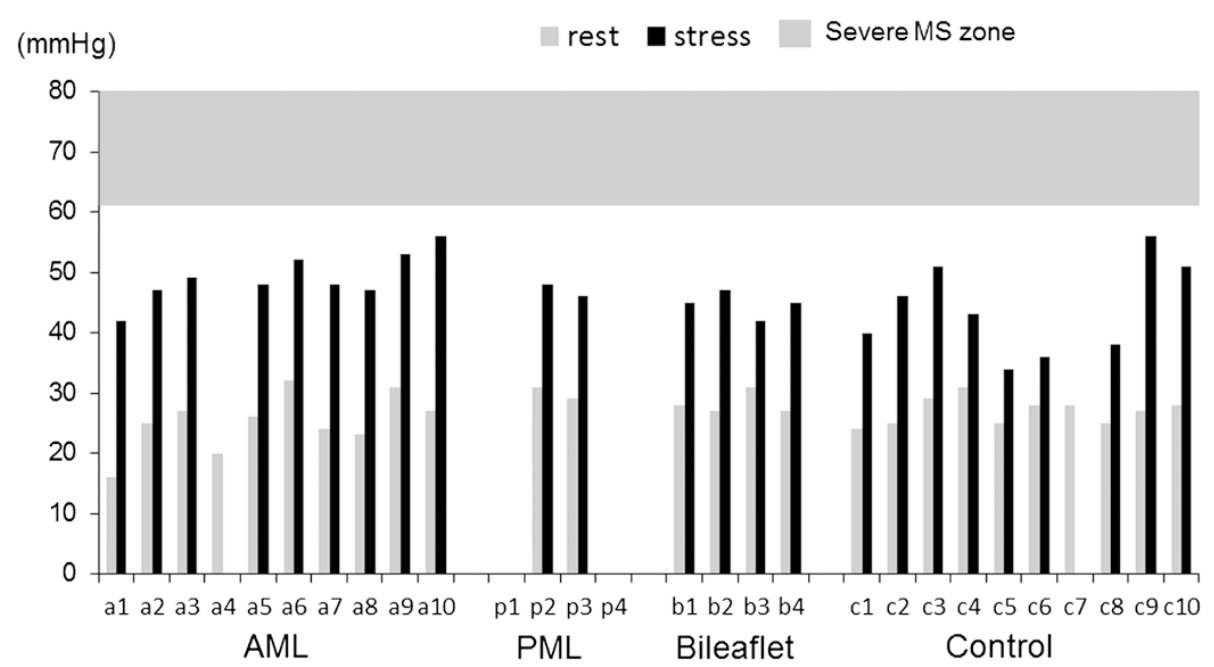

Figure 6 Echocardiographic data of systolic pulmonary artery pressure (sPAP). Echocardiographic data of systolic pulmonary artery pressure (SPAP) at rest and peak stress in AML, PML, bileaflet and control groups.

functional mitral stenosis. It was the only concern about RZT and we had to research about it.

\section{Evaluation of severity of mitral valve stenosis}

Stress (exercise or drug) echocardiography is useful for evaluating mitral valve stenosis [4] and the systolic pulmonary artery pressure at stress is an important parameter for preserving tolerance to exercise [11]. However, few reports have described stress (drug or exercise) echocardiography for evaluating mitral valve function after repair [12,13]. In this study, we applied dobutamine stress echocardiography to evaluate mitral valve function after repair using RZT. The echocardiographic findings of cardiac stress imposed by treadmill or ergometer exercise [14] or by administering drugs such as dobutamine are similar [15]. Since cardiovascular disease occurs in relatively elderly patients, we considered that exercise might not impose sufficient stress because of conditions such as gonarthrosis and arteriosclerosis obliterans. We therefore imposed stress during the echocardiographic study using dobutamine. Several investigators have adopted a maximum dobutamine dose of $40 \mu \mathrm{g} / \mathrm{Kg} / \mathrm{min}$ in the DSE protocol $[16,17]$, but dangerous arrhythmias caused some patients to abandon the study [17-19]. Some patients reached the target heart rate at that dose and $10 \mu \mathrm{g} / \mathrm{Kg} / \mathrm{min}$ was sufficient to generate cardiotonic action [20]. In fact, one study has limited the maximum dobutamine dose to $20 \mu \mathrm{g} / \mathrm{Kg} /$ min in DSE for evaluating mitral valve stenosis [21]. Safety was our top priority and thus we selected a maximum dobutamine dose of $20 \mu \mathrm{g} / \mathrm{Kg} / \mathrm{min}$.

\section{Considerations for the results from this study}

The MVA data were similar between the AML and PML groups, and slightly lower in the bileaflet group, but MVA increased at peak stress in all groups. Some investigators have found that MVA was overestimated at tachycardia in the PHT method [22,23], whereas Agricola et al. found that MVA was increased at exercise stress [12], indicating that a reserve mitral valve area might remain to increase cardiac output. The ACC/AHA criterion for severe mitral stenosis is MVmeanPG $>15 \mathrm{mmHg}$ or sPAP $>60 \mathrm{mmHg}$ on stress echocardiography and they recommend considering surgery [4]. No pathological findings to fulfill the criterion mentioned above were found in our patients after mitral valve repair or in healthy controls. However, MVmeanPG was somewhat elevated (>10 $\mathrm{mmHg}$ ) in two patients in the AML group (a1, a7) and one each in the PML (p2) and bileaflet (b2) groups. The MVA of one patient (a1) in the AML and of one (b2) in the bileaflet group were relatively small (1.8 and $2.3 \mathrm{~cm}^{2}$, respectively), which might have affected the MVmeanPG. However, the MVA was $3.0 \mathrm{~cm}^{2}$ in the other patient (a7) in the AML group and in one patient (p2) in the PML group, and their MVmeanPG was relatively high. The echocardiographic findings of patient a7 in the AML group indicated sclerotic changes at the anterior leaflet and curved transmitral blood flow due to surging against sclerotic AML tissue (Figure 7). Patient p2 in the PML group had sclerotic changes at the posterior leaflet and transmitral blood flow was directed towards the anterior leaflet. Color Doppler images showed a mosaic pattern near the AML suggesting that persistent sclerotic change or the 
Table 2 Hemodynamic data at rest and peak stress during dobutamine stress echocardiography

\begin{tabular}{|c|c|c|c|c|c|c|c|c|c|c|c|c|}
\hline \multirow[t]{2}{*}{ Variable } & \multicolumn{3}{|c|}{ AML $(n=10)$} & \multicolumn{3}{|l|}{ PML $(n=4)$} & \multicolumn{3}{|c|}{ Bileaflet $(n=4)$} & \multicolumn{3}{|c|}{ Control $(n=10)$} \\
\hline & Rest & Stress & $p$ & Rest & Stress & $p$ & Rest & Stress & $p$ & Rest & Stress & $p$ \\
\hline Mitral valve area $\left(\mathrm{cm}^{2}\right)$ & $2.8 \pm 0.4$ & $3.4 \pm 0.3$ & 0.0005 & $2.8 \pm 0.3$ & $3.2 \pm 0.3$ & 0.0010 & $2.5 \pm 0.1$ & $2.9 \pm 0.1$ & 0.0220 & $4.1 \pm 0.4$ & $5.1 \pm 0.5$ & 0.0001 \\
\hline MVmaxPG (mmHg) & $9.2 \pm 3.0$ & $16.3 \pm 6.0$ & 0.0079 & $12.0 \pm 2.5$ & $22.3 \pm 5.0$ & 0.0077 & $9.3 \pm 4.2$ & $17.5 \pm 4.7$ & 0.0071 & $3.8 \pm 0.9$ & $9.4 \pm 3.7$ & 0.0003 \\
\hline MVmeanPG (mmHg) & $3.3 \pm 1.1$ & $7.4 \pm 4.1$ & 0.0026 & $5.5 \pm 1.0$ & $10.5 \pm 2.4$ & 0.0058 & $3.5 \pm 1.7$ & $8.8 \pm 3.1$ & 0.0146 & $1.1 \pm 0.3$ & $3.6 \pm 0.7$ & 0.0222 \\
\hline sPAP (mmHg) & $25.7 \pm 4.7$ & $49.1 \pm 4.1$ & 0.0000 & $30 \pm 1.4$ & $47.0 \pm 1.4$ & a & $28.3 \pm 1.9$ & $44.8 \pm 2.1$ & 0.0034 & $26.9 \pm 2.3$ & $43.9 \pm 7.6$ & 0.0001 \\
\hline MR grade (mean) & $0.1 \pm 0.3$ & $0.1 \pm 0.3$ & - & 0 & 0 & - & $0.3 \pm 0.5$ & 0 & 0.3910 & 0 & 0 & - \\
\hline HR (beats/min) & $73 \pm 16$ & $107 \pm 24$ & 0.0002 & $76 \pm 2$ & $127 \pm 25$ & 0.0225 & $68 \pm 3$ & $111 \pm 19$ & 0.0138 & $64 \pm 11$ & $115 \pm 16$ & 0.0000 \\
\hline sBP (mmHg) & $115 \pm 13$ & $150 \pm 20$ & 0.0008 & $127 \pm 14.0$ & $143.3 \pm 26.5$ & 0.1495 & $115 \pm 14$ & $145 \pm 33$ & 0.1991 & $104 \pm 8$ & $153 \pm 18$ & 0.0000 \\
\hline $\mathrm{dBP}(\mathrm{mmHg})$ & $69 \pm 13$ & $71 \pm 13$ & 0.5426 & $76.3 \pm 9.2$ & $71 \pm 6.9$ & 0.1261 & $69 \pm 16$ & $75 \pm 17$ & 0.6440 & $53 \pm 9$ & $65 \pm 9$ & 0.0069 \\
\hline $\mathrm{CO}$ (L/min) & $4.4 \pm 1.0$ & $7.9 \pm 1.4$ & 0.0000 & $5.0 \pm 0.4$ & $9.6 \pm 2.5$ & 0.0234 & $4.2 \pm 0.3$ & $7.5 \pm 1.0$ & 0.0023 & $3.9 \pm 0.7$ & $9.2 \pm 1.4$ & 0.0000 \\
\hline EF (\%) & $64.7 \pm 2.9$ & $81.9 \pm 2.5$ & 0.0000 & $61.9 \pm 6.7$ & $81.9 \pm 4.5$ & 0.0006 & $62.8 \pm 1.5$ & $83.9 \pm 4.7$ & 0.0045 & $62.6 \pm 3.6$ & $82.0 \pm 2.7$ & 0.0000 \\
\hline LVEDV (ml) & $92.5 . \pm 10.3$ & $91.3 \pm 8.0$ & 0.5931 & $107.9 \pm 19.6$ & $89.4 \pm 13.5$ & 0.0262 & $98.3 \pm 10.7$ & $82.7 \pm 16.2$ & 0.0323 & $99.6 \pm 13.4$ & $99.0 \pm 14.0$ & 0.8726 \\
\hline LVESV (ml) & $31.7 \pm 4.7$ & $16.6 \pm 3.4$ & 0.0000 & $42.3 \pm 15.0$ & $15.0 \pm 4.6$ & 0.0195 & $36.5 \pm 3.7$ & $13.9 \pm 5.7$ & 0.0015 & $38.0 \pm 6.7$ & $18.1 \pm 5.4$ & 0.0000 \\
\hline
\end{tabular}

AML, anterior mitral leaflet; $C O$, cardiac output; dBP, diastolic blood pressure; $E F$, ejection fraction; LVEDV, left ventricular end diastolic volume; LVESV, left ventricular end systolic volume; MR, mitral valve regurgitation; $M V \max P G$, mitral valve maximum pressure gradient; $M V$ meanPG, mitral valve mean pressure gradient; $p, p$ value; $P M L$, posterior mitral leaflet; $s B P$, systolic blood pressure; $s P A P$, systolic pulmonary artery pressure.

aPML SPAP data were not statistically analyzed due to small sample size. 
Table 3 Echocardiographic comparison between AML and other groups that underwent mitral valve repair

\begin{tabular}{llllll}
\hline & Variable & AML & PML & Bileaflet & Control \\
\hline Rest & MVA $\left(\mathbf{c m}^{2}\right)$ & $2.8 \pm 0.4$ & $2.8 \pm 0.3$ & $2.5 \pm 0.1^{\mathrm{a}}$ & $4.1 \pm 0.4^{\mathrm{b}}$ \\
& MVmeanPG $(\mathbf{m m H g})$ & $3.3 \pm 1.1$ & $5.5 \pm 1.0^{\mathrm{a}}$ & $3.5 \pm 1.7$ & $1.1 \pm 0.3^{\mathrm{b}}$ \\
& sPAP $(\mathbf{m m H g})$ & $25.7 \pm 4.7$ & $30 \pm 1.4^{\mathrm{a}}$ & $28.3 \pm 1.9$ & $26.7 \pm 2.3$ \\
\hline Stress & Variable & AML & PML & Bileaflet & Control \\
& MVA (cm $\left.{ }^{2}\right)$ & $3.4 \pm 0.3$ & $3.2 \pm 0.3$ & $2.9 \pm 0.1^{\mathrm{b}}$ & $5.1 \pm 0.5^{\mathrm{b}}$ \\
& MVmeanPG $(\mathbf{m m H g})$ & $7.4 \pm 4.1$ & $10.5 \pm 2.4$ & $8.8 \pm 3.1$ & $3.6 \pm 0.7^{\mathrm{a}}$ \\
& SPAP $(\mathbf{m m H g})$ & $49.1 \pm 4.1$ & $47.0 \pm 1.4$ & $44.8 \pm 2.1^{\mathrm{a}}$ & $43.9 \pm 7.6$ \\
\hline
\end{tabular}

$\mathrm{AML}$, anterior mitral leaflet; MVA, mitral valve area; MVmeanPG, mitral valve mean pressure gradient; PML, posterior mitral leaflet; sPAP, systolic pulmonary artery pressure. ${ }^{\mathrm{a}} \mathrm{p}<0.05$ and ${ }^{\mathrm{b}} \mathrm{p}<0.01$ vs. AML.

direction of the transmitral flow affected MVmeanPG regardless of the MVA.

The MVmeanPG at rest and peak stress was significantly lower in healthy control than all groups after mitral valve repair. In mitral valve repair groups, the MVA was significantly reduced compared with healthy controls. Since MVA tends to decrease after mitral valve repair [24], not only control of regurgitation, but also functional preservation of the mitral valve should be carefully considered in the future.

We compared our results with those of other echocardiographic findings after mitral valve repair. Zucca et al. repaired mitral valve anterior leaflet prolapse by implanting artificial chordae. Their value for the mean MVA was $2.7 \mathrm{~cm}^{2}(2.2-3.0)$ [25]. Giovanni et al. performed DSE for patients with Barlow's disease who had been treated by mitral valve repair (AML: implanting of artificial chordae, PML: quadrangular resection for PML) [11]. Their values for mean MVA, MVmeanPG (rest/stress) and sPAP (rest/stress) were $2.7 \pm 0.7 \mathrm{~cm}^{2}, 2.7 / 6.3$ and $33.5 / 41.6 \mathrm{mmHg}$, respectively. Agricola et al. repaired mitral valves using the edge-to-edge procedure and investigated outcomes using exercise echocardiography [13]. Their values for mean MVA, MVmeanPG (rest/stress) and SPAP (rest/stress) were $3.2 \pm 0.6 \mathrm{~cm}^{2}, 2.8 / 4.6$ and $22.8 / 28.2 \mathrm{mmHg}$, respectively. Our findings after RZT for AML prolapse for MVA (rest), MVmeanPG (rest/stress) and SPAP (rest/stress) were $2.8 \pm 0.4 \mathrm{~cm}^{2}, 3.3 \pm 1.1 / 7.4 \pm$ 4.1, and $25.7 \pm 4.7 / 49.1 \pm 4.1 \mathrm{mmHg}$, respectively. Although our sPAP values were relatively high, they were similar to those of healthy controls. Thus, we considered that our values were equivalent to those reported, and that the RZT procedure is an appropriate and feasible technique.

\section{Limitations}

All prescribed drugs were continued during the study to consider the safety of the patients. The study cohort was small, because many patients had a history of serious diseases. Because of the nature of echocardiography, not all relevant parameters were measured and some were impossible to measure.

\section{Conclusions}

The Dobutamine stress echocardiography study for RZT revealed mitral valvular function reserve and no pathological obstruction. Novel mitral valve repair technique; RZT is simple, safe and reliable procedure.
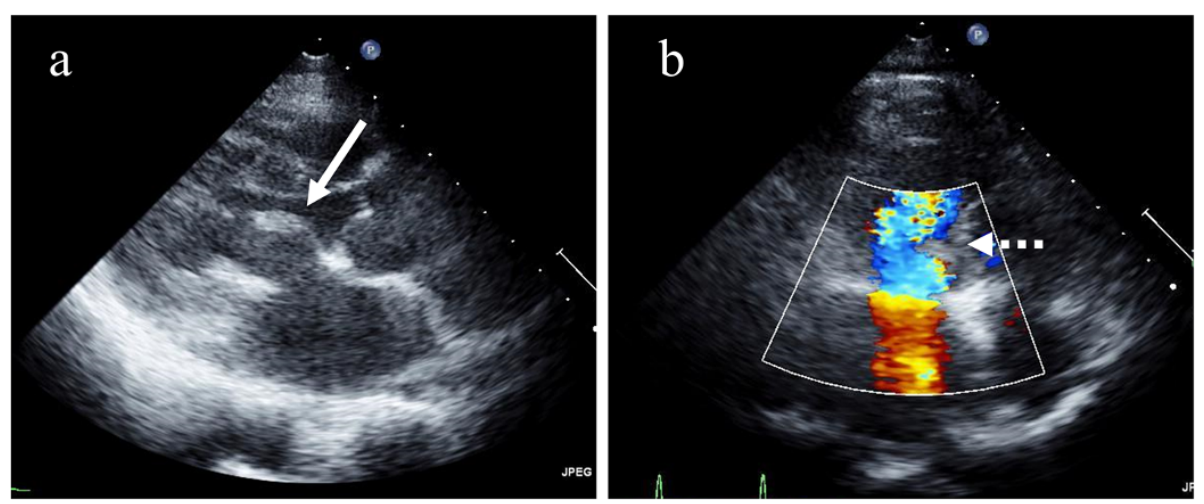

Figure 7 Postoperative echocardiographic images of anterior mitral leaflet (AML) plasty. (a) Long axis view. Sclerotic tissue remains in AML (white arrow). (b) Four chamber view. Mosaic pattern of transmitral blood flow near sclerotic tissue of AML on color Doppler image suggests that direction of transmitral blood flow became distorted by surging against sclerotic AML tissue (dotted arrow). 


\section{Abbreviations}

AML: Anterior mitral leaflet; CO: Cardiac output; dBP: Diastolic blood pressure; DSE: Dobutamine stress echocardiography; EF: Ejection fraction; ESS: Enhanced stay sutures; LVEDV: Left ventricular end diastolic volume; LVESV: Left ventricular end systolic volume; MVA: Mitral valve area; MR: Mitral valve regurgitation; MVmaxPG: Mitral valve maximum pressure gradient; MVmeanPG: Mitral valve mean pressure gradient; $p$ : P value; PML: Posterior mitral leaflet; QR: Quadrangular resection; RZT: Rough-zone trimming; SBP: Systolic blood pressure; SPAP: Systolic pulmonary artery pressure.

\section{Competing interests}

The authors declare that they have no competing interests.

\section{Authors' contributions}

YY conceived and designed the study, collected the patients' data and drafted the manuscript. NT helped to design the study, draft the manuscript. $H Y, T W, M U, K T, Y M$ and TI helped to design the study and collect the patients' data. TH developed the surgical techniques and helped to draft the manuscript. All authors read and approved the final manuscript.

\section{Acknowledgements}

We thank the Shionogi Drug Company for supplying the dobutamine applied in the present study.

Received: 25 June 2014 Accepted: 21 February 2015

Published online: 28 February 2015

\section{References}

1. Kay JH, Magidson O, Meihaus JE. The surgical treatment of mitral insufficiency and combined mitral stenosis and insufficiency using the heart-lung machine. Am J Cardiol. 1962;9:300-6.

2. Carpentier A, Relland J, Deloche A, Fabiani JN, D'Allaines C, Blondeau P, et al. Conservative management of the prolapsed mitral valve. Ann Thorac Surg. 1978;26:294-302.

3. Tachibana K, Higami T, Miyaki Y, Takagi N. Novel intraoperative evaluation for mitral valve regurgitation: retrograde cardioprotective beating test. EurJ Cardio-Thoracic Surg. 2013:44:375-6.

4. Bonow RO, Carabello BA, Chatterjee K, de Leon Jr AC, Faxon DP, Freed MD, et al. 2008 Focused update incorporated into the ACC/AHA 2006 guidelines for the management of patients with valvular heart disease: a report of the American College of Cardiology/American Heart Association Task Force on Practice Guidelines (Writing Committee to Revise the 1998 Guidelines for the Management of Patients With Valvular Heart Disease): endorsed by the Society of Cardiovascular Anesthesiologists, Society for Cardiovascular Angiography and Interventions, and Society of Thoracic Surgeons. Circulation. 2008:118:e523-661.

5. Kawano H, Mizoguchi T, Aoyagi S. Intraoperative transesophageal echocardiography for evaluation of mitral valve repair. J Heart Valve Dis. 1999;8:287-93.

6. Carpentier A, Chauvaud S, Fabiani JN, Deloche A, Relland J, Lessana A, et al. Reconstructive surgery of mitral valve incompetence: ten-year appraisal. J Thorac Cardiovasc Surg. 1980;79:338-48.

7. Zussa C, Polesel E, Rocco F, Valfre C. Artificial chordae in the treatment of anterior mitral leaflet pathology. Cardiovasc Surg. 1997;5:125-8.

8. Alfieri O, Maisano F. An effective technique to correct anterior mitral leaflet prolapse. J Card Surg. 1999;14:468-70.

9. Lawrie GM, Earle EA, Earle NR. Feasibility and intermediate term outcome of repair of prolapsing anterior mitral leaflets with artificial chordal replacement in 152 patients. Ann Thorac Surg. 2006;81:849-56. discussion 856.

10. Alfieri O, De Bonis M, Lapenna E, Regesta T, Maisano F, Torracca L, et al. "Edge-to-edge" repair for anterior mitral leaflet prolapse. Semin Thorac Cardiovasc Surg. 2004;16:182-7.

11. Song JK, Kang DH, Lee CW, Lee SG, Cheong SS, Hong MK, et al. Factors determining the exercise capacity in mitral stenosis. Am J Cardiol. 1996;78:1060-2.

12. Minardi G, Manzara C, Pulignano G, Luzi G, Maselli D, Casali G, et al. Rest and Dobutamine stress echocardiography in the evaluation of mid-term results of mitral valve repair in Barlow's disease. Cardiovasc Ultrasound. 2007:5:17.

13. Agricola E, Maisano F, Oppizzi M, De Bonis M, Torracca L, La Canna G, et al. Mitral valve reserve in double-orifice technique: an exercise echocardiographic study. J Heart Valve Dis. 2002;11:637-43.
14. Sagar KB, Wann LS, Paulson WJ, Lewis S. Role of exercise Doppler echocardiography in isolated mitral stenosis. Chest. 1987;92:27-30.

15. Hecker SL, Zabalgoitia M, Ashline P, Oneschuk L, O'Rourke RA, Herrera CJ. Comparison of exercise and dobutamine stress echocardiography in assessing mitral stenosis. Am J Cardiol. 1997;80:1374-7.

16. Reis G, Motta MS, Barbosa MM, Esteves WA, Souza SF, Bocchi EA Dobutamine stress echocardiography for noninvasive assessment and risk stratification of patients with rheumatic mitral stenosis. J Am Coll Cardiol. 2004;43:393-401

17. Mertes H, Sawada SG, Ryan T, Segar DS, Kovacs R, Foltz J, et al. Symptoms, adverse effects, and complications associated with dobutamine stress echocardiography. Experience in 1118 patients. Circulation. 1993;88:15-9.

18. Secknus MA, Marwick TH. Evolution of dobutamine echocardiography protocols and indications: safety and side effects in 3,011 studies over 5 years. J Am Coll Cardiol. 1997;29:1234-40.

19. Mathias Jr W, Arruda A, Santos FC, Arruda AL, Mattos E, Osorio A, et al. Safety of dobutamine-atropine stress echocardiography: A prospective experience of 4,033 consecutive studies. J Am Soc Echocardiogr. 1999;12:785-91.

20. Sakamoto T, Yamada T. Hemodynamic effects of dobutamine in patients following open heart surgery. Circulation. 1977;55:525-33.

21. Hwang MH, Pacold I, Piao ZE, Engelmeier R, Scanlon PJ, Loeb HS. The usefulness of dobutamine in the assessment of the severity of mitral stenosis. Am Heart J. 1986;111:312-6.

22. Braverman AC, Thomas JD, Lee RT. Doppler echocardiographic estimation of mitral valve area during changing hemodynamic conditions. Am J Cardiol. 1991;68:1485-90.

23. Mohan JC, Patel AR, Passey R, Gupta D, Kumar M, Arora R, et al. Is the mitral valve area flow-dependent in mitral stenosis? A dobutamine stress echocardiographic study. J Am Coll Cardiol. 2002;40:1809-15.

24. Hori H, Fukunaga S, Arinaga K, Yoshikawa K, Tayama E, Aoyagi S. Edge-to-edge repair for mitral regurgitation: a clinical and exercise echocardiographic study. J Heart Valve Dis. 2008;17:476-84.

25. Zussa C, Frater RW, Polesel E, Galloni M, Valfre C. Artificial mitral valve chordae: experimental and clinical experience. Ann Thorac Surg. 1990;50:367-73.

\section{Submit your next manuscript to BioMed Central and take full advantage of:}

- Convenient online submission

- Thorough peer review

- No space constraints or color figure charges

- Immediate publication on acceptance

- Inclusion in PubMed, CAS, Scopus and Google Scholar

- Research which is freely available for redistribution 